\title{
Erratum zu: Tausendsechshundert Seiten „Bildung““ Eine Sammelbesprechung
}

\author{
Ewald Terhart
}

Online publiziert: 31. Juli 2021

(C) Der/die Autor(en) 2021

\section{Erratum zu:}

\section{Z Erziehungswiss 2020}

https://doi.org/10.1007/s11618-020-00985-3

Der Artikel Tausendsechshundert Seiten „Bildung“. Eine Sammelbesprechung von Ewald Terhart wurde ursprünglich Online First ohne „Open Access“ auf der Internetplattform des Verlags publiziert. Nach der Veröffentlichung in Bd. 24 Heft 1 pp. 213-221 hatte sich der Autor für eine „Open Access“-Veröffentlichung entschieden. Das Urheberrecht des Artikels wurde deshalb in (C) Der/die Autor(en) 2021 geändert.

Funding Open Access funding enabled and organized by Projekt DEAL.

Open Access Dieser Artikel wird unter der Creative Commons Namensnennung 4.0 International Lizenz veröffentlicht, welche die Nutzung, Vervielfältigung, Bearbeitung, Verbreitung und Wiedergabe in jeglichem Medium und Format erlaubt, sofern Sie den/die ursprünglichen Autor(en) und die Quelle ordnungsgemäß nennen, einen Link zur Creative Commons Lizenz beifügen und angeben, ob Änderungen vorgenommen wurden.

Die in diesem Artikel enthaltenen Bilder und sonstiges Drittmaterial unterliegen ebenfalls der genannten Creative Commons Lizenz, sofern sich aus der Abbildungslegende nichts anderes ergibt. Sofern das betreffende Material nicht unter der genannten Creative Commons Lizenz steht und die betreffende Handlung

Die Online-Version des Originalartikels ist unter https://doi.org/10.1007/s11618-020-00985-3 zu finden.

Prof. i. R. Dr. Ewald Terhart (₫)

Institut für Erziehungswissenschaft, Universität Münster, Georgskommende 26, 48143 Münster,

Deutschland

E-Mail: ewald.terhart@uni-muenster.de 
nicht nach gesetzlichen Vorschriften erlaubt ist, ist für die oben aufgeführten Weiterverwendungen des Materials die Einwilligung des jeweiligen Rechteinhabers einzuholen.

Weitere Details zur Lizenz entnehmen Sie bitte der Lizenzinformation auf http://creativecommons.org/ licenses/by/4.0/deed.de. 